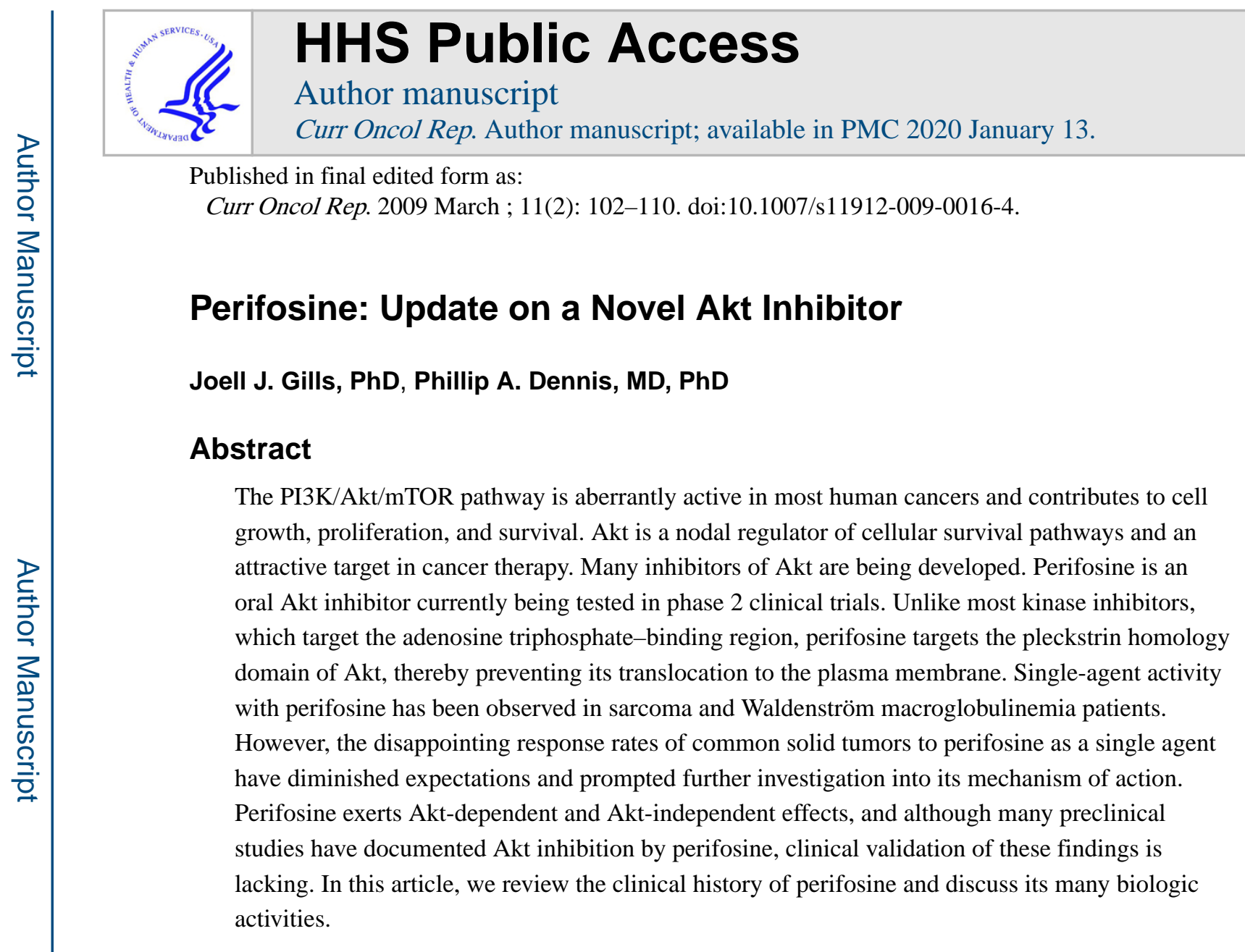

\title{
Introduction
}

The phosphoinositide-3 kinase (PI3K)/Akt/mammalian target of rapamycin (mTOR) pathway is an important signal transduction pathway that controls processes integral in cancer development, including protein translation, growth, metabolism, and survival. The $\mathrm{PI} 3 \mathrm{~K} / \mathrm{Akt} / \mathrm{mTOR}$ pathway is frequently activated in tumors and promotes therapeutic resistance, providing a strong rationale to target it in cancer therapy. Validation of this approach came with recognition that the mTOR inhibitor temsirolimus prolonged survival in renal cell cancer patients, which led to its US Food and Drug Administration approval. However, a possible mechanism of resistance to mTOR inhibitors is feedback activation of Akt, highlighting the need to develop agents that target other pathway components.

Akt is a serine/threonine kinase that lies upstream of mTOR in the pathway because Akt phosphorylates TSC2, which de-represses Rheb to interact with FKBP38 and allow mTOR activation [1]. Yet Akt also can be downstream of mTOR because the TORC2 complex consisting of mTOR and rictor (rapamycin-insensitive companion of mTOR) can phosphorylate Akt. Aberrant Akt activation may occur through overexpression or mutation of receptor tyrosine kinases, activation of oncogenes such as Ras, inactivation of the tumor

Corresponding author: Phillip A. Dennis, MD, PhD, Medical Oncology Branch, National Cancer Institute, NNMC, Building 8, Room 5101, 8901 Wisconsin Avenue, Bethesda, MD, 20889, USA.

Disclosures

No potential conflicts of interest relevant to this article were reported. 
suppressor PTEN (phosphatidylinositol phosphate 3'-phosphatase) through epigenetic silencing or mutations, activating mutations or amplification of isoforms of PI3K, or mutations in the pleckstrin homology $(\mathrm{PH})$ domain or genomic amplification of Akt itself. Akt is activated following activation of class I PI3K, which generates $\mathrm{PI}(3,4) \mathrm{P}_{2}\left(\mathrm{PIP}_{2}\right)$ and $\mathrm{PI}(3,4,5) \mathrm{P}_{3}\left(\mathrm{PIP}_{3}\right)$ (Fig. 1A). Once synthesized, $\mathrm{PIP}_{2}$ and $\mathrm{PIP}_{3}$ interact with the $\mathrm{PH}$ domain of Akt and cause its translocation to the plasma membrane, where it is phosphorylated on T308 by PDK1 and on S473 by the rictor/mTOR complex, as well as possibly by other proteins. Phosphorylation of both T308 and S473 is required for full kinase activity. Once phosphorylated, Akt dissociates from the plasma membrane and moves to various cellular compartments, where it can phosphorylate downstream substrates such as TSC2, FOXO, p21, p27, GSK3 $\beta$, BAD, XIAP, and MDM2.

Several Akt inhibitors have entered early-phase clinical trials. Triciribine is a nucleoside analogue that causes dephosphorylation of active Akt. Before its characterization as an Akt inhibitor, triciribine was evaluated as a cancer agent in multiple phase 1 and 2 trials. These trials showed that triciribine had modest activity and unexpected toxicity. Based on its newly recognized activity against Akt, it is in phase 1 trials focusing on Akt inhibition as well as traditional phase 1 end points. GSK690693 is an adenosine triphosphate (ATP)-competitive Akt inhibitor also in phase 1 clinical trials. XL418 is an agent that targets both Akt and p70S6K; however, after it began phase 1 testing, the trial was suspended because of low drug exposure. In addition, there are other ATP-competitive and allosteric Akt inhibitors in preclinical development [2]. It is too early to know which strategies might be successful, but specificity remains a challenge when targeting the ubiquitous ATP-binding pocket of kinases. A potentially more selective and novel approach is to target the lipid-binding PH domain of Akt, which is essential for its translocation and activation. This is the rationale behind the development of perifosine and other lipid-based Akt inhibitors [2].

\section{History of Development of Perifosine}

Perifosine is a synthetic oral alkylphospholipid (APL) with a piperidine head group. It belongs to a class of antitumor APLs that also includes edelfosine and miltefosine, and it was originally based on the structure of lysophos-phatidylcholine. APLs were shown to have selectivity for neoplastic versus normal hematologic cells in vitro. In vivo, perifosine induced thrombocytosis and leukocytosis and increased myelopoiesis in murine marrow and spleen, whereas it caused apoptosis in myeloma xenografts [3]. The reason for this selectivity is unknown. In vitro, perifosine inhibits Akt at low micromolar concentrations [4$11,12 \bullet \bullet, 13-21]$, and inhibition has been measured in many xenograft models in vivo [5,12••, $14,18,21]$. Thus far, the clinical results with perifosine have been modest and have not lived up to the hopes for an orally available Akt inhibitor (Table 1). However, few clinical trials with perifosine have evaluated Akt as a biomarker in patient tissues, leaving the question as to whether perifosine acts as an Akt inhibitor in humans or whether Akt inhibition is unimportant for growth of human cancers. 


\section{Clinical Summary}

In preclinical studies, a schedule using a loading dose of perifosine followed by successive maintenance doses improved efficacy and toxicity and thus was adopted for clinical trials, in which the maximum tolerated dose was determined to be $150 \mathrm{mg}$ orally in four loading doses and $100 \mathrm{mg} / \mathrm{d}$ for maintenance [22]. The maximum tolerated daily dose of perifosine is $200 \mathrm{mg} / \mathrm{kg}$ [23]. Unlike standard chemotherapies, perifosine induces limited bone marrow suppression. The major toxicities are gastrointestinal effects and fatigue. In phase 1 trials, partial responses were noted in one patient with sarcoma [22] and one patient with nonsmall cell lung cancer (NSCLC) [24]; stable disease was noted in three patients with prostate cancer [25], three patients with renal cell carcinoma [26], one patient with liver cancer, and one patient with ocular melanoma [23].

Sarcoma was one of the tumor types selected for phase 2 evaluation because of several durable responses noted during phase 1 trials [27]. However, in two phase 2 trials of perifosine in patients with mixed sarcoma subtypes, perifosine treatment led to a partial response in 1 of 23 patients with $9 \%$ progression-free at 6 months in one study [28], and no objective responses but stable disease in 4 of 19 patients in the other [27]. These results did not meet the criteria for either trial (ie, a minimum of $40 \%$ of patients progression-free at 6 months [28], or at least one objective response and no more than 11 early progressions [27], respectively). Subsequently, an analysis of 121 sarcoma patients culled from multiple phase 1 and 2 studies showed a clinical benefit rate for perifosine of 50\% [29]. A current phase 2 trial limited to chondrosarcoma and alveolar soft tissue sarcoma has reported promising activity—of 59 patients, 6 had a partial response and 13 had stable disease [30]. In addition to sarcoma, perifosine has shown promising activity in Waldenström's macroglobulinemia (WM) [31], with milder activity observed in multiple myeloma [32] and in a small set of hepatocellular carcinoma patients identified within a larger phase 2 trial [33]. However, a larger number of phase 2 trials of perifosine in prostate cancer [34,35], breast cancer [36], pancreatic cancer [37,38], melanoma [39], and head and neck cancer [40] have been disappointing (Table 1).

Despite the number of completed trials, the potential of perifosine as an Akt inhibitor in humans remains virtually unexplored. Only two studies measured Akt inhibition in patient tissues, both of which used levels of phosphorylated S473 as a surrogate for Akt activation. In a phase 2 trial of head and neck cancer, tumor biomarkers were measured by immunohistochemistry at baseline and in two patients before and after perifosine treatment [40]. In this unselected group, $64 \%$ of patient tumors had moderate or strong staining for S473 phosphorylation at baseline, and no decreases were noted in the post-perifosine biopsies. In a second study, perifosine reduced ex vivo clonogenic activity of $\mathrm{CD} 34^{+}$cells from patients with acute myelogenous leukemia (AML) displaying constitutive Akt activation, but not the clonogenic activity of $\mathrm{CD} 34^{+}$cells from AML patients without Akt activation [15]. 


\section{Important Preclinical Studies Related to Akt}

The cumulative preclinical evidence that perifosine targets Akt is convincing. Perifosine was first reported as an Akt inhibitor in 2003 [7,16]. It decreases Akt phosphorylation at S473 and T308, the two sites required for maximum kinase activity. Perifosine treatment followed by immunoprecipitation of Akt from PC3 cells decreased kinase activity in parallel with Akt dephosphorylation measured by immunoblotting [7]. In addition to downregulating endogenous active Akt, perifosine inhibits serum and growth factor-stimulated Akt, as well as insulin-stimulated movement of Akt to the plasma membrane. Akt inhibition is reversible since incubation with perifosine followed by washing and addition of fresh media led to recovery of phospho-Akt (P-Akt) [7]. The target of perifosine is the PH domain of Akt, based on its phospholipid structure. Overexpression of myristoylated Akt that is constitutively active (which bypasses the requirement for $\mathrm{PIP}_{3}$ binding to activate Akt) negates the effect of perifosine on Akt phosphorylation, whereas transfection of WT Akt does not [7]. Likewise, overexpression of constitutively active PI3K (CA-PI3K-p110a), but not WT, overcomes perifosine-mediated inhibition of P-Akt [7].

How is perifosine able to interfere with the PH domain? Preliminary data published in abstract form suggest that perifosine inhibits binding of the Akt PH domain to artificial membranes containing $3 \% \mathrm{PIP}_{2}\left(50 \%\right.$ inhibitory concentration $\left.\left[\mathrm{IC}_{50}\right]>10 \mu \mathrm{M}\right)$ [41]. In contrast, it did not inhibit binding of two other PH domain-containing proteins to membranes containing phosphoinositides [DAPP1 PH domain binding to $\mathrm{PIP}_{2}$ or PLC- $\delta-1$ $\mathrm{PH}$ domain binding to $\left.\mathrm{PI}(4,5) \mathrm{P}_{2}\left(\mathrm{IC}_{50}>100 \mu \mathrm{M}\right)\right]$. These findings suggest that perifosine selectively inhibits the $\mathrm{PH}$ domain of Akt, but the authors note that the binding of perifosine to the PH domain occurs with relatively low affinity and that direct binding by titration calorimetry could not be detected.

Akt inhibition by perifosine has been documented in vivo against myeloma [5], WM [18], prostate cancer [12••], and glioma $[14,21]$ xenografts in immune-compromised mice. The most comprehensive analysis of Akt inhibition in vivo was performed by Hennessy et al. [12••], who administered perifosine to tumor-bearing mice on different schedules. In PC3 and Du145 xenografts, there was significant correlation among the cumulative dose of perifosine, tumor growth inhibition, and decreases in phosphorylation of Akt and other pathway components in the tumors [12••]. In A431 and BT474 xenografts, perifosine was ineffective in inhibiting tumor growth and did not inhibit Akt. Thus, the ability of perifosine to inhibit Akt in tumors correlated with growth inhibition in vivo. To determine the pharmacodynamics of Akt inhibition, PC3 xenografts were treated with perifosine daily and tumors were harvested on days 1, 2, 7, and 21. Significant inhibition of Akt phosphorylation at S473 was observed 7 and 21 days after perifosine administration, which led the authors to recommend assessment of Akt phosphorylation as a biomarker 7 days after perifosine administration begins [12••]. In addition, cell lines with activating PI3/Akt genomic alterations (in PI3K, PTEN, and epidermal growth factor receptor [EGFR] overexpression) were more sensitive to perifosine in vitro than those without $[12 \bullet \bullet]$. 


\section{Other components of the pathway}

In addition to decreasing P-Akt, perifosine decreases phosphorylation of many downstream components, including P-p70S6K [12••],13], P-S6 [12••], P-4EBP-1 [13], P-GSK a/ $\beta$ $[5,6,12 \bullet \bullet]$, P-FKHRL1 [5,6], and P-S112 Bad [15]. Several reports suggest that perifosine does not seem to target upstream components of the PI3K/Akt/mTOR pathway, because it did not inhibit purified PI3K [7], and did not alter the levels of P-PDK1 [5,15], mTOR, raptor (regulatory associated protein of mTOR), or rictor [15]. However, the existence of a few reports showing that perifosine does affect upstream components suggests that Akt inhibition also may be indirect. For example, perifosine can inhibit insulin-stimulated PI3K activity in intact cells [16] and decrease PTEN and total Akt levels in NSCLC cells [6]. In addition, perifosine can increase phosphorylation of growth factor receptors that stimulate Akt, such as EGFR [12••]. The mechanism underlying these effects is unclear, but some may be attributable to disturbances in membrane structure or function.

\section{Perifosine and lipid rafts}

APLs target cell membranes [42], and the long hydrocarbon chain of perifosine suggests it can easily insert into phospholipid bilayers. Perifosine has a long half-life of 137 hours and is stable in vivo [43]; thus, it may accumulate and disturb regions of the membrane involved in signaling (Fig. 1B). Consistent with this, van der Luit et al. [44] showed that perifosine may be taken up through, and accumulate in, lipid rafts. Lipid rafts are cholesterol- and sphingolipid-rich microdomains that serve as scaffolds for signal transduction. These are likely important for Akt activation, because Akt has been isolated within raft fractions (Fig. 1A) [45]. Alterations in raft composition by perifosine have been shown by Gajate and Mollinedo [46•], who demonstrated that perifosine induces clustering of DR4, DR5, FAS/ CD95, FADD, and caspase 8 in leukemic raft fractions. Another way perifosine might disturb rafts is through increases in ceramide. Perifosine has been reported to elevate ceramide [47], a cytotoxic sphingolipid that also has the ability to downregulate Akt. In agreement with this finding, downregulation of sphingomyelin synthase I (SMSI) abrogates the toxicity of perifosine [44], and cells that were made resistant to edelfosine or perifosine [48•] had decreased levels of SMSI [49]. Because ceramide can be produced from sphingomyelin by the action of sphingomyelinases, this suggests that sphingolipid signaling could be important for the cytotoxicity and Akt inhibition associated with perifosine.

\section{Cytotoxic mechanism of perifosine}

In addition to targeting Akt, perifosine possesses other biologic activities that may contribute to its cytotoxicity. These include activation of p38 and JNK (7), inhibition of phosphatidylcholine synthesis [44], increased expression of p21 [50] and DR5 [6,46•,51], inhibition of migration and adhesion [18], downregulation of MEK and ERK phosphorylation [15], and decreased expression of P-glycoprotein [4], survivin, and $\beta$ catenin [10].

Perifosine may induce cytostatic $[9,13,50,52]$ or cytotoxic responses. In hematologic malignancies, perifosine primarily causes apoptosis through activation of the extrinsic 
pathway via stimulation of death receptors that increase cleavage of caspases 3,8 , and 9 . In these cells, critical mediators of perifosine-induced apoptosis include CD95/FAS [4,15,46•], lipid rafts $[4,44,46 \bullet$, and JNK [5,15], but not Akt [5]. In epithelial cancer cells, apoptosis $[6,8,16]$, cell cycle arrest $[9,13,50]$, or necrosis may result [9]. In NSCLC cells, perifosine caused apoptosis accompanied by an increase in DR5, a decrease in c-FLIP, and caspase 8 and 9 cleavage. Apoptosis was inhibited by expression of constitutively active Akt, as well as by small interfering RNA knockdown of caspase 8 and DR5 [6]. Thus, multiple mechanisms of action likely contribute to the anticancer effects of perifosine.

\section{Combination strategies with perifosine}

The concept of "oncogene addiction" asserts that some cancers depend on one gene or a few genes for their survival and maintenance of the malignant phenotype. Although PI3K/Akt/ mTOR pathway activation is required for the development and/or maintenance of certain stages of cancer, tumor heterogeneity and clinical experience suggest that combination therapy will be required to achieve remission or cure in most patients. In vitro, perifosine has been combined successfully with UCN-01 [53], histone deacetylase (HDAC) inhibitors [47], etoposide [11], TRAIL (tumor necrosis factor-related apoptosis-inducing ligand) [6,51], erlotinib [8], cetuximab [17], 17-DMAG [20], dexamethasone, doxorubicin, melphalan, and bortezomib [5]. In vitro, death by the combination of perifosine and HDAC inhibitors was shown to depend on Akt inhibition, ERK activation, and reactive oxygen and ceramide production [47]. With the combination of perifosine and TRAIL, death depended on DR4 and DR5 expression, but not Akt [51]. In mice bearing human tumors in vivo, combinations of perifosine and temozolomide [13] or radiation [54] have shown promise. In AML blasts, perifosine increased sensitivity to etoposide [15].

These preclinical data, combined with the observation that Akt inhibition increases the responsiveness to chemotherapy and radiation, have prompted several phase 1 combination studies with perifosine (Table 2). These include evaluation of perifosine combined with radiation [55], lenalidomide [56], sorafenib [57], sunitinib [58], docetaxel [59], paclitaxel [60,61], imatinib, or gemcitabine [62]. The most promising combination results have been in myeloma. In a phase 2 trial in patients with relapsed/refractory multiple myeloma, perifosine and dexamethasone achieved a partial or minimal response (MR) in 38\% and stable disease in $47 \%$ [32]. In a phase 1 trial of perifosine and bortezomib with or without dexamethasone, $20 \%$ of patients had a partial response or MR and $20 \%$ had stable disease with perifosine plus bortezomib, whereas 13\% had an MR and 20\% had stable disease with perifosine plus bortezomib and dexamethasone [63]. These combinations have advanced into a phase 2 trial. Given the promising activity observed in patients with myeloma and the accessibility of tumor cells in this malignancy, future trials with perifosine in multiple myeloma should analyze biomarkers to help determine the mechanism of action of perifosine in humans.

\section{Conclusions}

Although there is strong evidence that perifosine inhibits Akt in preclinical models of cancer, perifosine possesses Akt-independent activities as well. Death receptors, lipid rafts, and JNK also are important in the death caused by perifosine, depending on the cell type. In 
vitro, perifosine interferes with the normal function of the PH domain of Akt. Yet it remains unclear whether perifosine does so by disrupting membrane microdomains crucial to Akt activation (Fig. 1B) or whether it binds directly to the PH domain of Akt, thereby displacing the natural $\mathrm{PIP}_{2}$ and $\mathrm{PIP}_{3}$ ligands (Fig. 1C). Regardless, the most promising clinical results with perifosine have been in sarcoma and WM patients, but almost none of the reported trials attempted to measure Akt inhibition. Given the overall modest clinical activity observed with perifosine, it is crucial to develop reliable assays that measure Akt and to employ them in clinical trials with Akt inhibitors. If perifosine inhibits Akt and the clinical response is poor, this would cast doubt on existing assumptions about the value of Akt as a target in cancer. If Akt is not inhibited, this should prompt examination of Akt-independent mechanism(s) of action or pharmacodynamic properties of perifosine, to better guide the clinical development of this unusual agent.

\section{References and Recommended Reading}

Papers of particular interest, published recently, have been highlighted as:

- Of importance

•- Of major importance

1. Bai X, Ma D, Liu A, et al.: Rheb activates mTOR by antagonizing its endogenous inhibitor, FKBP38. Science 2007, 318:977-980. [PubMed: 17991864]

2. LoPiccolo J, Granville CA, Gills JJ, Dennis PA: Targeting Akt in cancer therapy. Anticancer Drugs 2007, 18:861-874. [PubMed: 17667591]

3. Catley L, Hideshima T, Chauhan D, et al.: Alkyl phospholipid perifosine induces myeloid hyperplasia in a murine myeloma model. Exp Hematol 2007, 35:1038-1046. [PubMed: 17588472]

4. Chiarini F, Del Sole M, Mongiorgi S, et al.: The novel Akt inhibitor, perifosine, induces caspasedependent apoptosis and downregulates P-glycoprotein expression in multidrug-resistant human Tacute leukemia cells by a JNK-dependent mechanism. Leukemia 2008, 22:1106-1116. [PubMed: 18385752]

5. Hideshima T, Catley L, Yasui H, et al.: Perifosine, an oral bioactive novel alkylphospholipid, inhibits Akt and induces in vitro and in vivo cytotoxicity in human multiple myeloma cells. Blood 2006, 107:4053-4062. [PubMed: 16418332]

6. Elrod HA, Lin YD, Yue P, et al.: The alkylphospholipid perifosine induces apoptosis of human lung cancer cells requiring inhibition of Akt and activation of the extrinsic apoptotic pathway. Mol Cancer Ther 2007, 6:2029-2038. [PubMed: 17604333]

7. Kondapaka SB, Singh SS, Dasmahapatra GP, et al.: Perifosine, a novel alkylphospholipid, inhibits protein kinase B activation. Mol Cancer Ther 2003, 2:1093-1103. [PubMed: 14617782]

8. Festuccia C, Gravina GL, Muzi P, et al.: Akt down-modulation induces apoptosis of human prostate cancer cells and synergizes with EGFR tyrosine kinase inhibitors. Prostate 2008, 68:965-974. [PubMed: 18361408]

9. Floryk D, Thompson TC: Perifosine induces differentiation and cell death in prostate cancer cells. Cancer Lett 2008, 266:216-226. [PubMed: 18395973]

10. Hideshima T, Catley L, Raje N, et al.: Inhibition of Akt induces significant downregulation of survivin and cytotoxicity in human multiple myeloma cells. Br J Haematol 2007, 138:783-791. [PubMed: 17760810]

11. Nyakern M, Cappellini A, Mantovani I, Martelli AM: Synergistic induction of apoptosis in human leukemia T cells by the Akt inhibitor perifosine and etoposide through activation of intrinsic and Fas-mediated extrinsic cell death pathways. Mol Cancer Ther 2006, 5:1559-1570. [PubMed: 16818515] 
12••. Hennessy BT, Lu Y, Poradosu E, et al.: Pharmacodynamic markers of perifosine efficacy. Clin Cancer Res 2007, 13:7421-7431. [PubMed: 18094426] This article provides a comprehensive analysis of perifosine dose and schedule on P-Akt and other biomarkers. It establishes a correlation among perifosine cumulative dose, P-Akt inhibition, and tumor growth inhibition in vivo.

13. Momota H, Nerio E, Holland EC: Perifosine inhibits multiple signaling pathways in glial progenitors and cooperates with temozolomide to arrest cell proliferation in gliomas in vivo. Cancer Res 2005, 65:7429-7435. [PubMed: 16103096]

14. de la Pena L, Burgan WE, Carter DJ, et al.: Inhibition of Akt by the alkylphospholipid perifosine does not enhance the radiosensitivity of human glioma cells. Mol Cancer Ther 2006, 5:1504-1510. [PubMed: 16818509]

15. Papa V, Tazzari PL, Chiarini F, et al.: Proapoptotic activity and chemosensitizing effect of the novel Akt inhibitor perifosine in acute myelogenous leukemia cells. Leukemia 2008, 22:147-160. [PubMed: 17928881]

16. Ruiter GA, Zerp SF, Bartelink H, et al.: Anti-cancer alkyl-lysophospholipids inhibit the phosphatidylinositol 3-kinase-Akt/PKB survival pathway. Anticancer Drugs 2003, 14:167-173. [PubMed: 12569304]

17. Li X, Luwor R, Lu Y, et al.: Enhancement of antitumor activity of the anti-EGF receptor monoclonal antibody cetuximab/C225 by perifosine in PTEN-deficient cancer cells. Oncogene 2006, 25:525-535. [PubMed: 16170346]

18. Leleu X, Jia X, Runnels J, et al.: The Akt pathway regulates survival and homing in Waldenstrom macroglobulinemia. Blood 2007, 110:4417-4426. [PubMed: 17761832]

19. Vinall RL, Hwa K, Ghosh P, et al.: Combination treatment of prostate cancer cell lines with bioactive soy isoflavones and perifosine causes increased growth arrest and/or apoptosis. Clin Cancer Res 2007, 13:6204-6216. [PubMed: 17947488]

20. Huston A, Leleu X, Jia X, et al.: Targeting Akt and heat shock protein 90 produces synergistic multiple myeloma cell cytotoxicity in the bone marrow microenvironment. Clin Cancer Res 2008, 14:865-874. [PubMed: 18245550]

21. Zhang L, Lee KC, Bhojani MS, et al.: Molecular imaging of Akt kinase activity. Nat Med 2007, 13:1114-1119. [PubMed: 17694068]

22. Van Ummersen L, Binger K, Volkman J, et al.: A phase I trial of perifosine (NSC 639966) on a loading dose/maintenance dose schedule in patients with advanced cancer. Clin Cancer Res 2004, 10:7450-7456. [PubMed: 15569974]

23. Crul M, Rosing H, de Klerk GJ, et al.: Phase I and pharmacological study of daily oral administration of perifosine (D-21266) in patients with advanced solid tumours. Eur J Cancer 2002, 38:1615-1621. [PubMed: 12142051]

24. Henderson IC, Spigel DR, Nemunaitis JJ, et al.: A phase I study of weekly, divided dose perifosine in patients with non-small cell lung cancer. J Clin Oncol 2006, 24:13060.

25. Monga M, Messmann RA, Headlee D, et al.: A phase I trial of perifosine in patients with refractory neoplasms [abstract]. Proc Am Soc Clin Oncol 2002, 21:1837.

26. Stephenson J, Schreeder M, Waples J, et al.: Perifosine, active as a single agent for renal cell carcinoma, now in phase I trials combined with tyrosine kinase inhibitors. J Clin Oncol 2007, 25:15622.

27. Knowling M, Blackstein M, Tozer R, et al.: A phase II study of perifosine (D-21226) in patients with previously untreated metastatic or locally advanced soft tissue sarcoma: a National Cancer Institute of Canada Clinical Trials Group trial. Invest New Drugs 2006, 24:435-439. [PubMed: 16528479]

28. Bailey HH, Mahoney MR, Ettinger DS, et al.: Phase II study of daily oral perifosine in patients with advanced soft tissue sarcoma. Cancer 2006, 107:2462-2467. [PubMed: 17058289]

29. Birch R, Chawla S, Nemunaitis J, et al.: Perifosine as an active agent in the treatment of patient with advanced sarcoma. J Clin Oncol 2007, 25(18S):10059.

30. Steinert D, Henderson C, Chawla S, et al.: A phase II trial of perifosine in patients with chemoinsensitive sarcomas - study update [abstract 860]. Presented at the 13th Annual Meeting of the Connective Tissue Oncology Society Seattle, WA; November 1-3, 2007. 
31. Ghobrial IM, Leleu X, Rubin N, et al.: Phase II trial of the novel oral Akt inhibitor perifosine in relapsed and/or refractory Waldenstrom macroglobulinemia [abstract]. J Clin Oncol 2008, 26:8546.

32. Richardson P, Lonial S, Jakubowiak A, et al.: Multi-center phase II study of perifosine alone and in combination with dexamethasone for patients with relapsed or refractory multiple myeloma: promising activity as combination therapy with manageable toxicity [abstract]. Blood 2007, 110:1164.

33. Campos LT, Stephenson J, Swan F, et al.: Daily dose of perifosine less toxic than weekly and active in patients with hepatocellular carcinoma [abstract]. J Clin Oncol 2007, 25(18S):15072.

34. Posadas EM, Gulley J, Arlen PM, et al.: A phase II study of perifosine in androgen independent prostate cancer. Cancer Biol Ther 2005, 4:1133-1137. [PubMed: 16138006]

35. Chee KG, Longmate J, Quinn DI, et al.: The AKT inhibitor perifosine in biochemically recurrent prostate cancer: a phase II California/Pittsburgh cancer consortium trial. Clin Genitourin Cancer 2007, 5:433-437. [PubMed: 18272025]

36. Leighl NB, Dent S, Clemons M, et al.: A phase 2 study of perifosine in advanced or metastatic breast cancer. Breast Cancer Res Treat 2008, 108:87-92. [PubMed: 17458693]

37. Marsh Rde W, Rocha Lima CM, Levy DE, et al.: A phase II trial of perifosine in locally advanced, unresectable, or metastatic pancreatic adenocarcinoma. Am J Clin Oncol 2007, 30:26-31. [PubMed: 17278891]

38. Hedley D, Moore MJ, Hirte H, et al.: A phase II trial of perifosine as a second line therapy for advanced pancreatic cancer. A study of the Princess Margaret Hospital Phase II Consortium. J Clin Oncol 2005, 23:4166.

39. Ernst DS, Eisenhauer E, Wainman N, et al.: Phase II study of perifosine in previously untreated patients with metastatic melanoma. Invest New Drugs 2005, 23:569-575. [PubMed: 16034524]

40. Argiris A, Cohen E, Karrison T, et al.: A phase II trial of perifosine, an oral alkylphospholipid, in recurrent or metastatic head and neck cancer. Cancer Biol Ther 2006, 5:766-770. [PubMed: 16760642]

41. Poradosu E, Lemmon M, Keleti D: Perifosine selectively inhibits binding of Akt PH domain to PtdIns(3,4)P2 Proceedings of the American Association for Cancer Research Annual Meeting (2007). Philadelphia: AACR; 2007:1645.

42. Arthur G, Bittman R: The inhibition of cell signaling pathways by antitumor ether lipids. Biochim Biophys Acta 1998, 1390:85-102. [PubMed: 9487143]

43. Vink SR, Schellens JH, van Blitterswijk WJ, Verheij M: Tumor and normal tissue pharmacokinetics of perifosine, an oral anti-cancer alkylphospholipid. Invest New Drugs 2005, 23:279-286. [PubMed: 16012787]

44. van der Luit AH, Vink SR, Klarenbeek JB, et al.: A new class of anticancer alkylphospholipids uses lipid rafts as membrane gateways to induce apoptosis in lymphoma cells. Mol Cancer Ther 2007, 6:2337-2345. [PubMed: 17699729]

45. Lasserre R, Guo XJ, Conchonaud F, et al.: Raft nanodomains contribute to Akt/PKB plasma membrane recruitment and activation. Nat Chem Biol 2008, 4:538-547. [PubMed: 18641634]

46•. Gajate C, Mollinedo F: Edelfosine and perifosine induce selective apoptosis in multiple myeloma by recruitment of death receptors and downstream signaling molecules into lipid rafts. Blood 2007, 109:711-719. [PubMed: 17003375] This article details changes in lipid raft composition in response to perifosine.

47. Rahmani M, Reese E, Dai Y, et al.: Coadministration of histone deacetylase inhibitors and perifosine synergistically induces apoptosis in human leukemia cells through Akt and ERK1/2 inactivation and the generation of ceramide and reactive oxygen species. Cancer Res 2005, 65:2422-2432. [PubMed: 15781658]

48• Vink SR, van der Luit AH, Klarenbeek JB, et al.: Lipid rafts and metabolic energy differentially determine uptake of anti-cancer alkylphospholipids in lymphoma versus carcinoma cells. Biochem Pharmacol 2007, 74:1456-1465. [PubMed: 17803969] This article shows that perifosine is taken up through and accumulates in lipid rafts. 
49. Van der Luit AH, Budde M, Zerp S, et al.: Resistance to alkyl-lysophospholipid-induced apoptosis due to downregulated sphingomyelin synthase 1 expression with consequent sphingomyelin- and cholesterol-deficiency in lipid rafts. Biochem J 2007, 401:541-549. [PubMed: 17049047]

50. Patel V, Lahusen T, Sy T, et al.: Perifosine, a novel alkylphospholipid, induces p21(WAF1) expression in squamous carcinoma cells through a p53-independent pathway, leading to loss in cyclin-dependent kinase activity and cell cycle arrest. Cancer Res 2002, 62:1401-1409. [PubMed: 11888912]

51. David E, Sinha R, Chen J, et al.: Perifosine synergistically enhances TRAIL-induced myeloma cell apoptosis via up-regulation of death receptors. Clin Cancer Res 2008, 14:5090-5098. [PubMed: 18698026]

52. Martelli AM, Papa VS, Tazzari PL, et al.: The novel Akt inhibitor perifosine induces apoptosis, cell cycle arrest and synergizes with chemotherapeutic drugs in acute myelogenous leukemia cells by a JNK dependent mechanism - a novel therapeutic approach for leukemia displaying elevated Akt signaling [abstract]. Blood (ASH Annual Meeting Abstracts) 2007, 110:3355.

53. Dasmahapatra GP, Didolkar P, Alley MC, et al.: In vitro combination treatment with perifosine and UCN-01 demonstrates synergism against prostate (PC-3) and lung (A549) epithelial adenocarcinoma cell lines. Clin Cancer Res 2004, 10:5242-5252. [PubMed: 15297428]

54. Vink SR, Lagerwerf S, Mesman E, et al.: Radiosensitization of squamous cell carcinoma by the alkylphospholipid perifosine in cell culture and xenografts. Clin Cancer Res 2006, 12:1615-1622. [PubMed: 16533789]

55. Vink SR, Schellens JH, Beijnen JH, et al.: Phase I and pharmacokinetic study of combined treatment with perifosine and radiation in patients with advanced solid tumours. Radiother Oncol 2006, 80:207-213. [PubMed: 16914220]

56. Jakubowiak A, Zimmerman T, Alsina M, et al.: A multiple myeloma research consortium multicenter phase I trial of perifosine in combination with lenalidomide and dexamethasone in patients with relapsed/refractory multiple myeloma: updated results [abstract]. Blood 2007, 110:1169.

57. Schreeder MT, Figlin RA, Stephenson JJ, et al.: Phase I multicenter trial of perifosine in combination with sorafenib for patients with advanced cancers including renal cell carcinoma [abstract]. J Clin Oncol 2008, 26:16024.

58. Allerton JP, Ebrahimi B, Schreeder MT, et al.: Phase I report from a multicenter trial of perifosine and sunitinib in patients with advanced cancers including renal cell carcinoma [abstract]. J Clin Oncol 2008, 26:14565.

59. Cervera A, Bernhardt B, Nemunaitis JJ, et al.: Perifosine can be combined with docetaxel without dose reduction of either drug. J Clin Oncol 2006, 24:13066.

60. Goggins TF, Nemunaitis JJ, Schiffman R, et al.: A phase I study of daily oral perifosine with every 3-week paclitaxel. J Clin Oncol 2006, 24:13134.

61. Ebrahimi B, Nemunaitis JJ, Shiffman R, et al.: A phase I study of daily oral perifosine with weekly paclitaxel [abstract]. J Clin Oncol 2006, 24:13117.

62. Weiss S, Nemunaitis JJ, Diaz-Lacayo M, et al.: A phase I study of daily oral perifosine and weekly gemcitabine [abstract]. J Clin Oncol 2006, 24:13084.

63. Richardson P, Jakubowiak A, Wolf J, et al.: Phase I/II report from a multicenter trial of perifosine and bortezomib in patients with relapsed or relapsed/refractory multiple myeloma previously treated with bortezomib [abstract]. Blood 2007, 110:1170. 


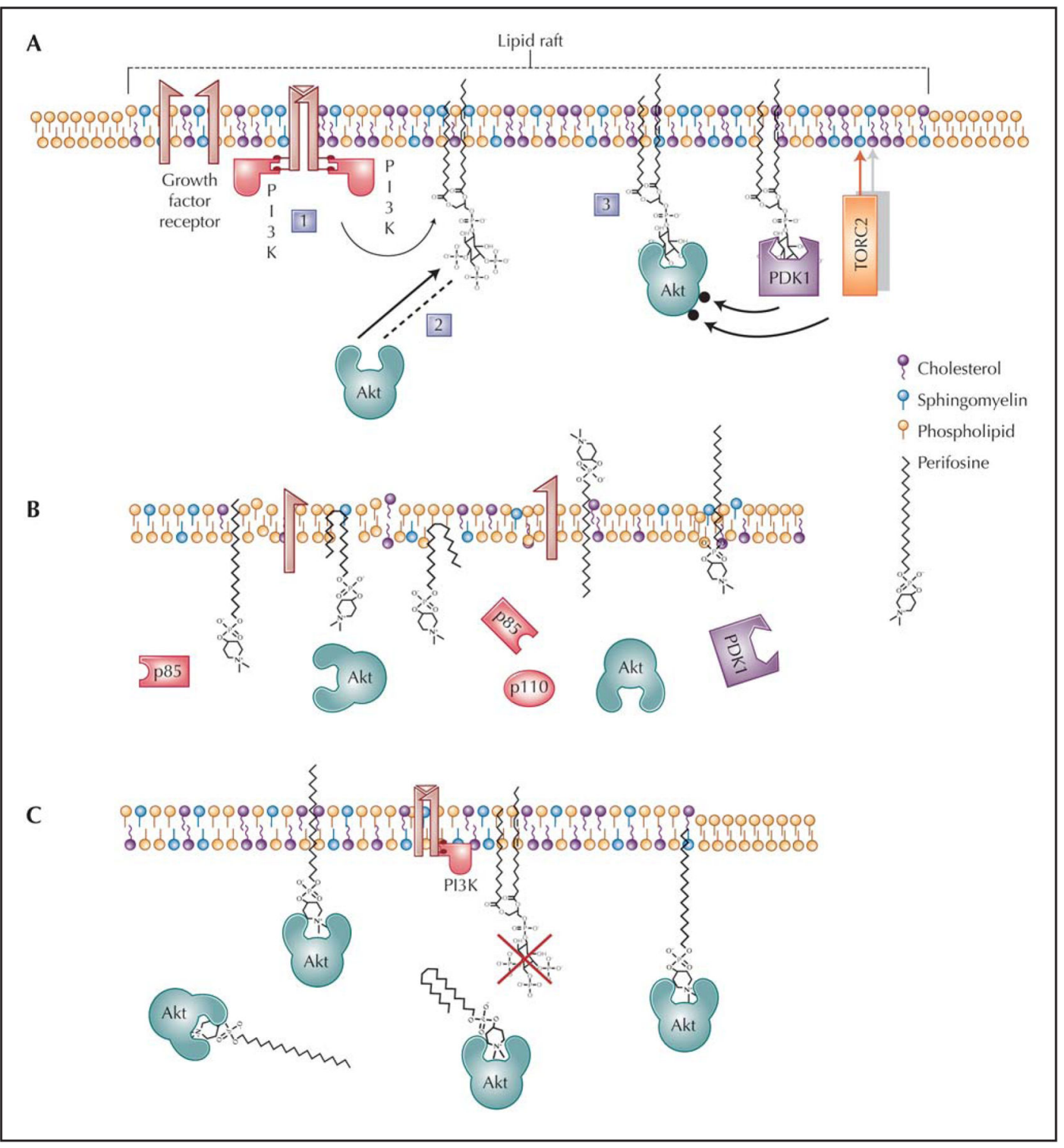

Figure 1.

Events leading to Akt activation and potential inhibitory mechanism(s) of perifosine. A, Akt activation in lipid rafts. 1) Growth factor receptor activation via ligand binding recruits phosphoinositide-3 kinase (PI3K), which converts $\mathrm{PI}(4) \mathrm{P}$ to $\mathrm{PI}(3,4) \mathrm{P}_{2}$ and $\mathrm{PI}(4,5) \mathrm{P}_{2}$ to $\mathrm{PI}(3,4,5) \mathrm{P}_{3}$. 2) The pleckstrin homology $(\mathrm{PH})$ domain of Akt binds to $\mathrm{PI}(3,4) \mathrm{P}_{2}$ or $\mathrm{PI}(3,4,5) \mathrm{P}_{3}$ (depicted here) at the membrane. 3) Akt is activated at the membrane via phosphorylation at T308 by PDK1 and at S473 by the TORC2 complex. B and C, Possible mechanisms of action of perifosine. B, Perifosine disrupts the structure of and signaling within lipid rafts, preventing Akt recruitment to the membrane. C, Perifosine binds directly to and inhibits the PH domain of Akt. 


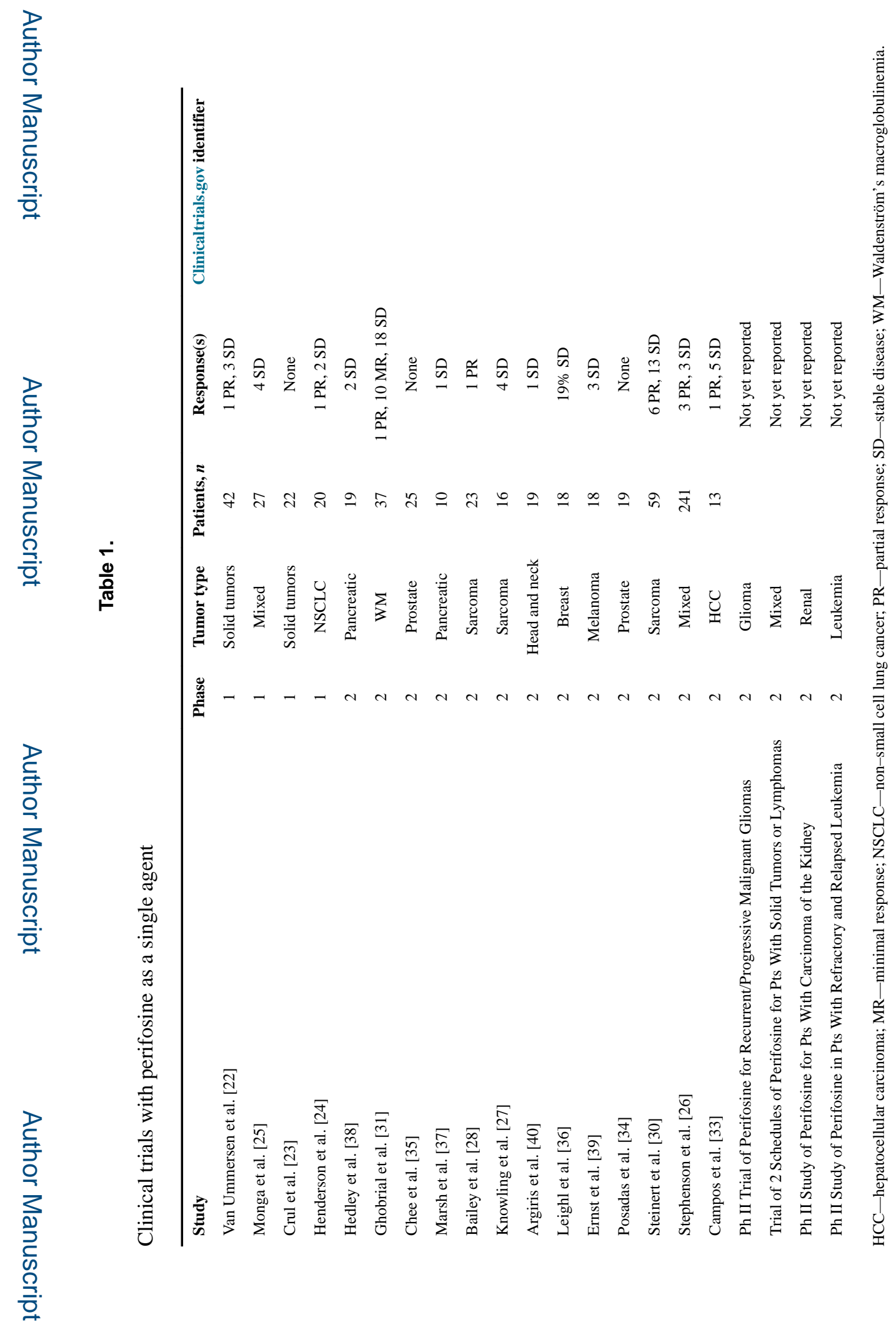

Curr Oncol Rep. Author manuscript; available in PMC 2020 January 13. 


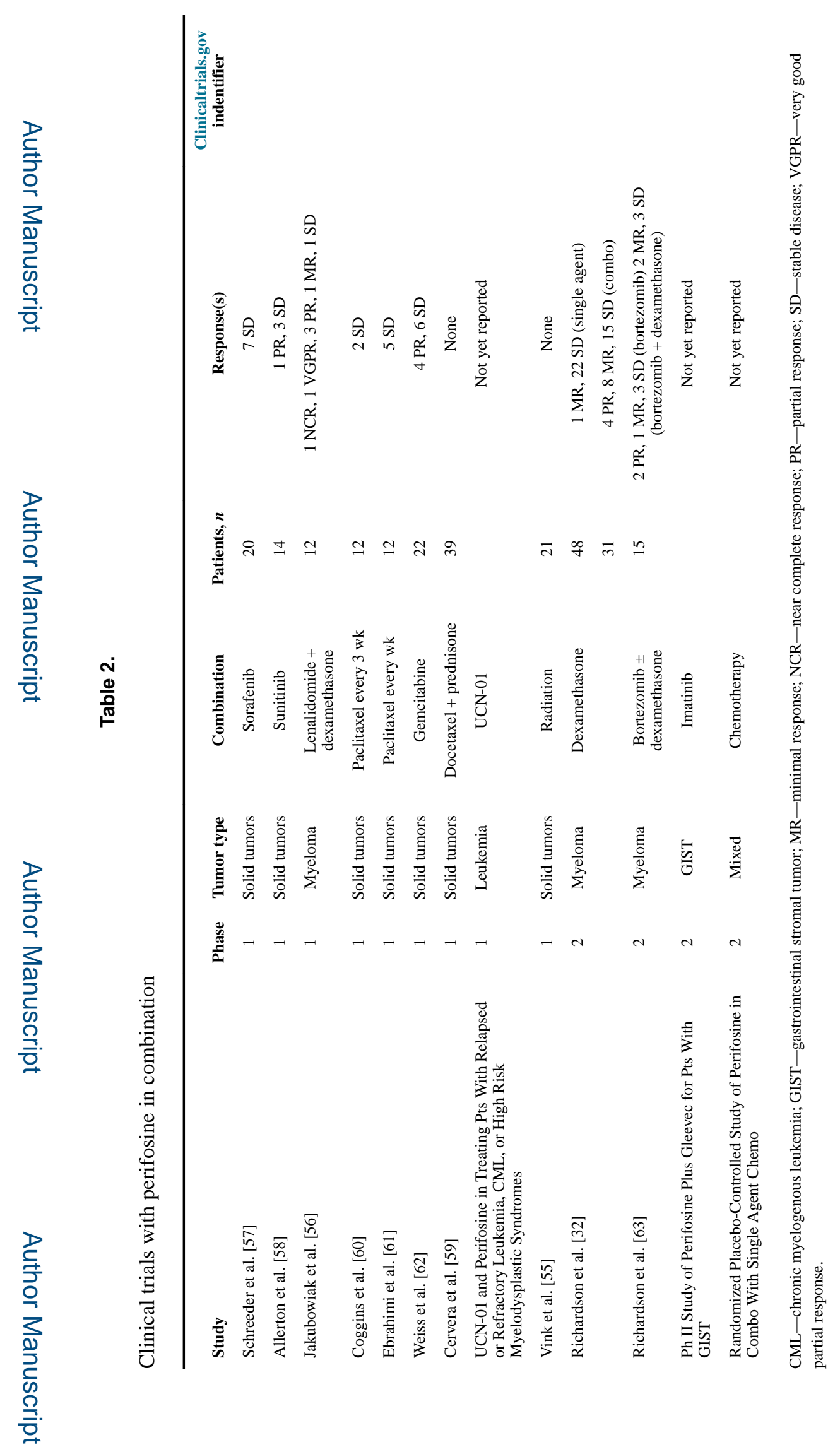

Curr Oncol Rep. Author manuscript; available in PMC 2020 January 13. 